
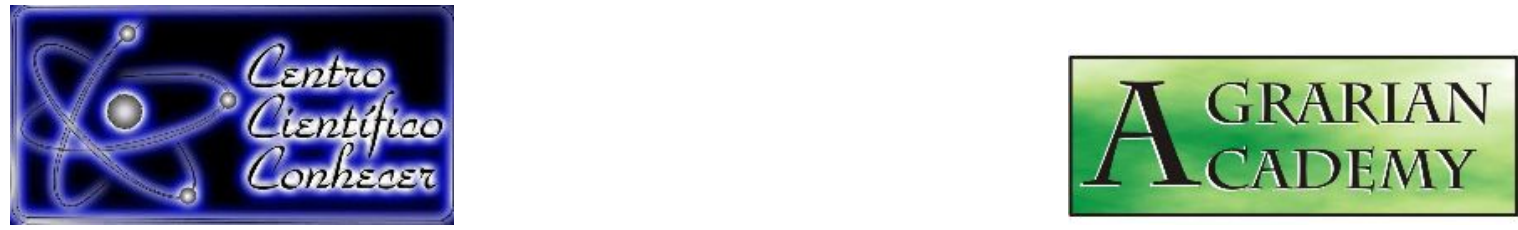

\title{
APLICAÇÃO DO SISTEMA DE AVALIAÇÃO DA APTIDÃO AGRÍCOLA DAS TERRAS (SAAAT) EM SOLOS DO NORTE DE MINAS GERAIS
}

\section{Eduardo Carvalho da Silva Neto ${ }^{1}$, Andressa Fabiane Faria de Souza ${ }^{2}$; Marcondes Geraldo Coelho Júnior ${ }^{3}$; Ana Amélia dos Santos Cordeiro ${ }^{4}$; Athila Leandro de Oliveira ${ }^{5}$}

${ }^{1}$ Doutorando em Agronomia/Ciência do Solo, Universidade Federal Rural do Rio de Janeiro

(UFRRJ), Seropédica/RJ, Brasil, netocseduardo@gmail.com

${ }^{2}$ Doutoranda em Agronomia/Ciência do Solo, UFRRJ

${ }^{3}$ Mestrando em Ciências Ambientais e Florestais, UFRRJ

${ }^{4}$ Professora no Instituto Federal do Norte de Minas, Campus Arinos

${ }^{5}$ Doutorando em Ciências Ambientais e Florestais, UFRRJ

Recebido em: 14/07/2018 - Aprovado em: 28/07/2018 - Publicado em: 31/07/2018 DOI: 10.18677/Agrarian_Academy_2018a4

\begin{abstract}
RESUMO
A avaliação da aptidão agrícola possibilita a identificação do potencial produtivo das terras, oferecendo importantes subsídios para planejamento do uso e manejo do solo de forma sustentável. O objetivo desse trabalho foi avaliar o potencial agrícola das terras da região Norte de Minas Gerais e propor alternativas para sua adequação de uso. Os perfis de solo analisados foram reclassificados de acordo com o Sistema Brasileiro de Classificação de Solos e as classes de aptidão determinadas de acordo com o Sistema de Avaliação de Aptidão Agrícola das Terras para a elaboração dos mapas atualizados de solo e aptidão agrícola. O levantamento de solos, a nível intermediário entre exploratório e reconhecimento, compreende a mesorregião Norte do estado de Minas Gerais. Esta região apresentou terras com aptidão para cultivo silvícola e terras que permitem o cultivo agrícola. Não foram encontradas, todavia, terras com aptidão boa para lavoura. As principais limitações dos solos estão relacionadas à deficiência hídrica, fertilidade, mecanização e susceptibilidade a erosão. Diante do exposto se faz necessário assegurar práticas que possibilitem a exploração sustentável dos recursos naturais e o desenvolvimento integrado da região.
\end{abstract}

PALAVRAS-CHAVE: Avaliação das terras; Cerrado; Uso do solo.

\section{APPLICATION OF THE LAND AGRICULTURAL FACILITY ASSESSMENT SYSTEM (SAAAT) IN SOILS OF THE NORTH OF MINAS GERAIS}

\section{ABSTRACT}

Evaluation systems of agricultural land suitability allows the identification of the productive potential of the lands, offering important subsidies for planning the use and management of the soil in a sustainable way. The objective of this study was to evaluate the land suitability of the Northern region of Minas Gerais and to propose alternatives for their suitability of use. The analyzed soil profiles were reclassified AGRARIAN ACADEMY, Centro Científico Conhecer - Goiânia, v.5, n.9; p. 30 
according to the Brazilian Soil Classification System and the land suitability classes determined according to the Agricultural Aptitude Assessment System of the Lands for the elaboration of updated soil and agricultural aptitude maps. Soil survey, at intermediate level between exploratory and reconnaissance, comprises the northern mesoregion of the state of Minas Gerais. The northern mesoregion of Minas presented lands with aptitude for silvicultural cultivation and lands that allow agricultural cultivation. However, no land with good cropping ability was found. The main limitations of soils are related to water deficiency, fertility, mechanization and susceptibility to erosion. In view of the above, it is necessary to ensure practices that enable the sustainable exploitation of natural resources and the integrated development of the region.

KEYWORDS: Land evaluation; Brazilian Savanna; Land use.

\section{INTRODUÇÃO}

A interpretação dos levantamentos de solos é uma tarefa de grande relevância para sua utilização na agricultura. Dentre as aplicações funcionais mais importantes para o uso e a ocupação sustentável desse recurso no meio rural, destaca-se a avaliação da aptidão agrícola das terras, que constitui a base para realização dos zoneamentos agrícolas, agroecológicos por culturas e ecológicoeconômico. Os trabalhos de interpretação podem ainda ser utilizados por outros setores que utilizam o solo como elemento integrante de suas atividades, como o setor civil e industrial (FLAUZINO et al., 2016).

O planejamento de uso da terra viabiliza alternativas para a exploração sustentável dos recursos naturais mediante a adequação das diferentes formas de uso agrícola (PEREIRA; LOMBARDI NETO, 2004; WADT et al., 2004; WADT et al., 2013). Nesse contexto, os sistemas de classificação taxonômicos aliados aos sistemas de classificação técnica, que preconizam a capacidade de uso e sustentabilidade da terra, permitem diagnosticar problemas e propor soluções na relação do homem com o meio ambiente, constituindo ferramentas importantes para o desenvolvimento socioeconômico sustentável.

A avaliação da aptidão agrícola possibilita não apenas a identificação do potencial produtivo das terras, nas suas diferentes categorias de uso e manejo, mas também oferece importantes subsídios para planejamentos do uso e manejo do solo de forma sustentável. O Sistema de Avaliação de Aptidão Agrícola das Terras (RAMALHO FILHO; BEEK, 1995) baseia-se em síntese, na interpretação de levantamento de solos, das características do ambiente por meio da avaliação e estimativa das limitações das terras para uso agrícola e das possibilidades de uso mais adequado de uma determinada área, contemplando as distintas alternativas de práticas de manejo. Isto é, trata-se de um processo interpretativo que considera informações sobre características de meio ambiente, de atributos do solo e da viabilidade de melhoramento de qualidades básicas das terras.

O Norte de Minas é a maior das meso-regiões mineiras, ocupando uma área de 128 mil km² e abrangendo 89 Municípios (IBGE, 2015). Situa-se em uma região de transição biológica entre os biomas Cerrado e Caatinga. No processo de formação socioeconômica dessa região, houve uma apropriação desigual do território, gerando a formação de enormes latifúndios. (GONÇALVES, 2000; SILVA et al., 2012)). A implantação de grandes projetos de pecuária e monoculturas extensivas, além de uma pesada política de subsídios e financiamentos a empreendimentos de perfil urbano-industrial, têm gerado algumas consequências 
negativas na região, como o aprofundamento das desigualdades entre os municípios, a exclusão social, a perda da biodiversidade e o comprometimento da oferta de água e de outros serviços ecossistêmicos. De acordo com Angelis Filho (2005) grande parte dessa região é ocupada por florestas de eucalipto e pastagens extensivas, inviabilizando o desenvolvimento socioeconômico de milhares de pequenos agricultores, que têm cada vez mais dificuldade em acessar recursos como terra, água, frutos nativos, ervas medicinais e lenha.

Considerando a necessidade de formulação e aplicação de estratégias econômicas baseadas nas culturas e nos ecossistemas locais para um desenvolvimento mais justo e ecologicamente equilibrado, o objetivo desse trabalho foi avaliar o potencial agrícola de áreas da região e propor alternativas para sua adequação de uso.

\section{MATERIAL E MÉTODOS}

O norte de Minas encontra-se no domínio geomorfológico da depressão periférica do Rio São Francisco. Área caracterizada por planaltos residuais, em sua maior parte recobertas com depósitos sedimentares areníticos de idade cretácea, com chapadas e formas médio-onduladas mais suaves, além de depressões interplanálticas e planície às margens dos rios. Apresenta cotas altimétricas que variam entre 400 a 1200 metros e no complexo do espinhaço existe a presença de altas superfícies aplainadas e escarpas acentuadas (IBGE, 2015). O relevo característico é bastante ondulado ou até montanhoso. Tal característica do relevo limita a prática de atividades agrícolas, assim como a pouca profundidade deste solo e presença de pedregosidade e rochosidade. Os afloramentos rochosos, que constituem tipos de terreno, não sendo classificáveis como solos, possuem um relevo bastante variado, desde plano até escarpado, com o predomínio daqueles acidentados: escarpado, montanhoso e forte ondulado (NEVES et al., 2015; GONÇALVES et al., 2017).

O clima da região Norte de Minas Gerais é predominantemente tropical com inverno seco, classificado como Aw (Koppen). Caracteriza-se por épocas mais secas que compreende os meses de junho a agosto e são registradas precipitações de no máximo $40 \mathrm{~mm} / \mathrm{mês}$, com estação chuvosa que compreende os meses de dezembro a fevereiro, com as precipitações médias de $200 \mathrm{~mm} / \mathrm{mês}$. Na rede hidrográfica do norte de Minas se destaca a bacia do Rio São Francisco, que possui $2.700 \mathrm{Km}$ de extensão, flui em direção sul-norte e recebe importantes afluentes na região. O clima do Médio São Francisco possui características de uma área tropical semiárida (ALMEIDA, 2017).

As diferentes formas de relevo em Minas Gerais, somadas às especificidades de solo e clima, propiciaram paisagens muito variadas, recobertas por vegetações características, adaptadas a cada um dos inúmeros ambientes particulares inseridos no domínio de três biomas brasileiros: o Cerrado, a Mata Atlântica e a Caatinga (MARTINS, 2006; ALMEIDA, 2017).

A vegetação do bioma Cerrado apresenta fisionomias que englobam formações florestais, savânicas e campestres. Em sentido fisionômico, floresta representa áreas com predominância de espécies arbóreas, onde há formação de dossel, contínuo ou descontínuo. A caatinga, apesar da aparência pobre e árida, se revela como um ecossistema complexo, apresentando em alguns trechos uma mata rala ou mais arbustiva, e em outros trechos o solo aparece quase descoberto, possuindo arbustos isolados (JOLY, 1970).

AGRARIAN ACADEMY, Centro Científico Conhecer - Goiânia, v.5, n.9; p. 32 
Os produtos cartográficos digitais e dados dos perfis de solos (análises físicas e químicas) utilizados na realização da pesquisa foram obtidos pelo Levantamento exploratório de reconhecimento de solos do Norte de Minas Gerais (JACOMINE et al., 1979). Os perfis analisados foram reclassificados de acordo com o Sistema Brasileiro de Classificação de Solos (SANTOS et al., 2013) e as classes de aptidão determinadas de acordo com o Sistema de Avaliação de Aptidão Agrícola das Terras (RAMALHO FILHO; BEEK, 1995). O levantamento de solos, a nível intermediário entre exploratório e reconhecimento, compreende a mesorregião Norte do estado de Minas Gerais, localizada entre os meridianos de $41^{\circ}$ e $46^{\circ}$ e os paralelos de $14^{\circ} \mathrm{e}$ $18^{\circ}$, numa extensão de aproximadamente $120.701 \mathrm{~km}^{2}$. No desenvolvimento da prospecção pedológica foram utilizados mapas planialtimétricos (Esc. 1:500.000 e 1:100.000) bem como, mosaicos semi-controlados e mapas geomorfológicos (Esc. $1: 250.000)$. As imagens foram importadas para uma base de dados no software livre Q-GIS para a elaboração dos mapas atualizados de solo e aptidão agrícola.

\section{RESULTADOS E DISCUSSÃO}

A reclassificação dos solos de acordo com o Sistema Brasileiro de Classificação de Solos - SiBCS (SANTOS et al., 2013), e os parâmetros analisados são apresentados na Tabela 1. A legenda preliminar de identificação dos solos da área foi elaborada pela Coordenadoria Regional do Nordeste do Serviço Nacional de Levantamento e Conservação de Solos (SNLCS) da Empresa Brasileira de Pesquisa Agropecuária (EMBRAPA), na época vinculada ao Ministério da Agricultura, através do Convênio de Mapeamento de Solos EMBRAPA/SNLCS-SUDENE/DRN (JACOMINE et al., 1979). A partir de 1977, começou grande demanda por uma classificação brasileira de solos. O desafio para o estabelecimento de um sistema de classificação brasileira de solos foi assumido, em 1978, pelo então Serviço Nacional de Levantamento e Conservação de Solos - SNLCS (sucessor da antiga Comissão de Solos) da EMBRAPA, por meio do Projeto: "Desenvolvimento do Sistema Brasileiro de Classificação de Solos". Mais informações sobre a origem e evolução do SiBCS podem ser encontradas em Anjos et al. (2012).

As principais mudanças na classificação foram em solos com horizonte $B$ textural não hidromórficos, com argila de atividade baixa, que correspondiam às classes de grande parte dos Podzólicos, reclassificados para Argissolos VermelhoAmarelos. As antigas Terras Roxas e Terras Roxas Estruturadas, de acordo com a nova classificação enquadram-se na ordem nos Nitossolos, grupamento de solos com horizonte $B$ nítico abaixo do horizonte $A$. O critério para sua identificação é o desenvolvimento (expressão) de horizonte $B$ nítico, em sequência a qualquer tipo de horizonte $A$, com pequeno gradiente textural, porém apresentando estrutura em blocos subangulares ou angulares, ou prismática, de grau moderado ou forte, com cerosidade expressiva ou superfícies brilhantes nas unidades estruturais, ou caráter retrátil (SANTOS et al., 2009; ANJOS et al., 2012; SANTOS et al., 2013).

Também foram reclassificados os Solos Litólicos Distróficos e Eutróficos e as Areias Quartzosas Distróficas, que pertencem atualmente à ordem dos Neossolos, grupamento de solos pouco evoluídos, com predomínio de características herdadas do material originário, sem horizonte $B$ diagnóstico definido. O critério para sua identificação é a insuficiência de expressão dos atributos diagnósticos que caracterizam os diversos processos de formação, com individualização de horizonte diagnóstico superficial seguido de C ou R (SANTOS et al., 2013). 
QUADRO 1. Reclassificação dos solos da mesorregião Norte de Minas segundo SiBCS (SANTOS et al., 2013).

\begin{tabular}{|c|c|c|c|}
\hline Cód. & Clasificação antiga & $\begin{array}{c}\text { Classificação } \\
\text { atual }\end{array}$ & Justificativa \\
\hline PVd4 & $\begin{array}{l}\text { PODZÓLICO VERMELHO- AMARELO ÁLICO Tb } \\
\text { A moderado textura argilosa cascalhenta/ muito } \\
\text { argilosa cascalhenta fase pedregosa cerrado } \\
\text { subcadocifólio relevo ondulado }\end{array}$ & $\begin{array}{l}\text { ARGISSOLO } \\
\text { VERMELHO } \\
\text { AMARELO }\end{array}$ & Adequação ao Sistema \\
\hline PVd4 & $\begin{array}{c}\text { PODZÓLICO VERMELHO-AMARELO } \\
\text { DISTRÓFICO Tb A moderado textura média } \\
\text { cascalhenta /argilosa cascalhenta fase floresta } \\
\text { caducifólia relevo ondulado }\end{array}$ & $\begin{array}{l}\text { ARGISSOLO } \\
\text { VERMELHO } \\
\text { AMARELO }\end{array}$ & Adequação ao Sistema \\
\hline PE9 & $\begin{array}{c}\text { PODZÓLICO VERMELHO-AMARELO } \\
\text { EUTRÓFICO Tb A moderado textura média/ } \\
\text { argilosa fase caatinga hipoxerófila relevo suave } \\
\text { ondulado }\end{array}$ & $\begin{array}{l}\text { ARGISSOLO } \\
\text { VERMELHO } \\
\text { AMARELO }\end{array}$ & $\begin{array}{c}\text { Apresenta B textural } \\
\text { matizes } 7,5 \mathrm{YR}, 5 \mathrm{YR} \mathrm{e} \\
2,5 \mathrm{YR}\end{array}$ \\
\hline PE5 & $\begin{array}{l}\text { PODZÓLICO VERMELHO-AMARELO } \\
\text { EUTRÓFICO Tb A moderado textura média com } \\
\text { cascalho/argilosa com cascalho fase floresta } \\
\text { caducifólia relevo ondulado }\end{array}$ & $\begin{array}{l}\text { ARGISSOLO } \\
\text { VERMELHO } \\
\text { AMARELO }\end{array}$ & Adequação ao Sistema \\
\hline Ca1 & $\begin{array}{l}\text { CAMBISSOLO ÁLICO Tb A moderado textura } \\
\text { argilosa fase cerrado subcaducifólio relevo } \\
\text { ondulado substrato siltito }\end{array}$ & $\begin{array}{l}\text { CAMBISSOLO } \\
\text { HÁPLICO }\end{array}$ & $\begin{array}{l}\text { Horizonte } B \text { incipiente, } \\
\text { não se adequou } \\
\text { nenhuma das demais } \\
\text { subordens }\end{array}$ \\
\hline Re3 & $\begin{array}{c}\text { CAMBISSOLO EUTRÓFICO Ta A chernozémico } \\
\text { textura argilosa fase floresta/caatinga relevo } \\
\text { ondulado substrato calcário }\end{array}$ & $\begin{array}{l}\text { CHERNOSSOLO } \\
\text { HÁPLICO }\end{array}$ & $\begin{array}{c}\text { A chernozênico } \\
\text { sobrejacente ao } \\
\text { horizonte B incipiente, } \\
\text { não se encaixou em às } \\
\text { demais subordens }\end{array}$ \\
\hline Ae2 & $\begin{array}{c}\text { GLEY POUCO HÚMICO EUTRÓFICO Tb A } \\
\text { moderado textura argilosa fase floresta caducifólia } \\
\text { de várzea relevo plano }\end{array}$ & $\begin{array}{l}\text { GLEISSOLO } \\
\text { HÁPLICO }\end{array}$ & $\begin{array}{l}\text { Horizonte } C \text { glei, não } \\
\text { se encaixou em } \\
\text { nenhuma das demais } \\
\text { subordens }\end{array}$ \\
\hline LVe1 & $\begin{array}{l}\text { LATOSSOLO VERMELHO- AMARELO } \\
\text { EUTRÓFICO podzólico A moderado textura média } \\
\text { fase caatinga hipoxerófila relevo plano }\end{array}$ & $\begin{array}{l}\text { LATOSSOLO } \\
\text { AMARELO }\end{array}$ & $\begin{array}{c}\text { Horizonte B latossólico, } \\
\text { matizes } 7,5 \text { e } 10 \mathrm{YR} \\
\text { nos primeiros } 100 \mathrm{~cm}\end{array}$ \\
\hline LVa25 & $\begin{array}{l}\text { LATOSSOLO VERMELHO- AMARELO ÁLICO A } \\
\text { moderado textura argilosa fase floresta/ caatinga } \\
\text { relevo plano }\end{array}$ & $\begin{array}{l}\text { LATOSSOLO } \\
\text { AMARELO }\end{array}$ & $\begin{array}{l}\text { Horizonte B latossólico, } \\
\text { matizes } 10 \mathrm{YR} \text { e } 5 \mathrm{YR} \\
\text { nos primeiros } 100 \mathrm{~cm}\end{array}$ \\
\hline LEe5 & $\begin{array}{l}\text { LATOSSOLO VERMELHO-ESCURO } \\
\text { EUTRÓFICO A moderado textura argilosa fase } \\
\text { caatinga hipoxerófila relevo suave ondulado }\end{array}$ & $\begin{array}{l}\text { LATOSSOLO } \\
\text { VERMELHO }\end{array}$ & $\begin{array}{l}\text { Horizonte B latossólico, } \\
\text { matiz } 10 \mathrm{R} \text { nos } \\
\text { primeiros } 100 \mathrm{~cm} \text { do } \\
\text { horizonte } \mathrm{B}\end{array}$ \\
\hline LEa1 & $\begin{array}{l}\text { LATOSSOLO VERMELHO-ESCURO ÀLICO A } \\
\text { proeminente textura muito argilosa fase cerrado } \\
\text { subcaducifólio relevo suave ondulado }\end{array}$ & $\begin{array}{l}\text { LATOSSOLO } \\
\text { VERMELHO }\end{array}$ & $\begin{array}{l}\text { Horizonte B latossólico, } \\
\text { matiz } 2,5 Y R \text { nos } \\
\text { primeiros } 100 \mathrm{~cm} \text { do } \\
\text { horizonte B }\end{array}$ \\
\hline LVa23 & $\begin{array}{l}\text { LATOSSOLO VERMELHO-ESCURO } \\
\text { DISTRÓFICO A moderado textura média fase } \\
\text { cerrado subcaducifólio relevo suave ondulado }\end{array}$ & $\begin{array}{l}\text { LATOSSOLO } \\
\text { VERMELHO }\end{array}$ & Adequação ao Sistema \\
\hline LEe7 & $\begin{array}{l}\text { LATOSSOLO VERMELHO-ESCURO } \\
\text { EUTRÓFICO A moderado textura argilosa fase }\end{array}$ & $\begin{array}{l}\text { LATOSSOLO } \\
\text { VERMELHO }\end{array}$ & Adequação ao Sistema \\
\hline
\end{tabular}


transição floresta/caatinga relevo plano

\section{PE9 EUTRÓFICO câmbico A moderado textura} argilosa fase caatinga hipoxerófila relevo ondulado

LVa19

LVa7

LVa30

LEa5

Ae2

Ra8

TRSe4

AQa4

\section{AREIA QUARTZOSA DISTRÓFICA A moderado} fase caatinga hipoxerófila relevo plano

TERRA ROXA ESTRUTURADA SIMILAR

TRSe1 EUTRÓFICA A moderado textura muito argilosa fase floresta caducifólia relevo suave ondulad.

TERRA ROXA ESTRUTURADA SIMILAR ÁLICA A TRSa moderado textura muito argilosa fase transição floresta caducifólia/cerrado relevo plano
LATOSSOLO

VERMELHO

LATOSSOLO

VERMELHO

LATOSSOLO

VERMELHO-

AMARELO

LATOSSOLO

VERMELHOAMARELO

LATOSSOLO

VERMELHO-

AMARELO

NEOSSOLO

FLÚVICO

NEOSSOLO

LITÓLICO

NEOSSOLO

LITÓLICO

NEOSSOLO QUARTZARÊNICO

NITOSSOLO HÁPLICO

NITOSSOLO VERMELHO
Horizonte B latossólico, matiz $10 \mathrm{R}$ nos primeiros $100 \mathrm{~cm}$ do horizonte $B$

Bw matizes 2,5 YR ou mais vermelho nos primeiros $100 \mathrm{~cm}$

Horizonte B latossólico, matizes 10YR e 5YR nos primeiros $100 \mathrm{~cm}$

Adequação ao Sistema

Adequação ao Sistema

Solo sem horizonte B, apresenta caráter flúvico

Adequação ao Sistema

Solo com horizonte A chernozemico assente diretamente sobre a rocha

Solo sem horizonte $B$, sequência $A C$ e sem contato lítico nos primeiros $50 \mathrm{~cm}$

Horizonte $\mathrm{B}$ nítico, matiz mais amarelo que 2,5 YR, não se encaixou em nenhuma das demais subordens.

Horizonte B nítico, matiz mais vermelha que 2,5YR nos primeiros $100 \mathrm{~cm}$

A partir da reclassificação dos solos (classificação taxonômica) e análise dos dados físicos, químicos e morfológicos dos perfis, foram produzidos os mapas de solo (Figura 1) e posteriormente os mapas de aptidão agrícola da região do Norte de Minas (Figura 2). Pela análise do mapa, pode-se observar que predominam na região solos muito intemperizados, com destaque para a ordem dos Latossolos (Latossolos Vermelho-Amarelos, Latossolos Amarelos e Latossolos Vermelhos). Esses solos são típicos das regiões equatoriais e tropicais, ocorrendo também em zonas subtropicais, distribuídos, sobretudo, por amplas e antigas superfícies de 
erosão, pedimentos ou terraços fluviais antigos, normalmente em relevo plano e suave ondulado, embora possam ocorrer em áreas mais acidentadas, inclusive em relevo montanhoso. São solos em avançado estádio de intemperização, em geral, solos fortemente ácidos, com baixa saturação por bases, distróficos ou alumínicos (KAMPF; CURI, 2012; SANTOS et al., 2013).

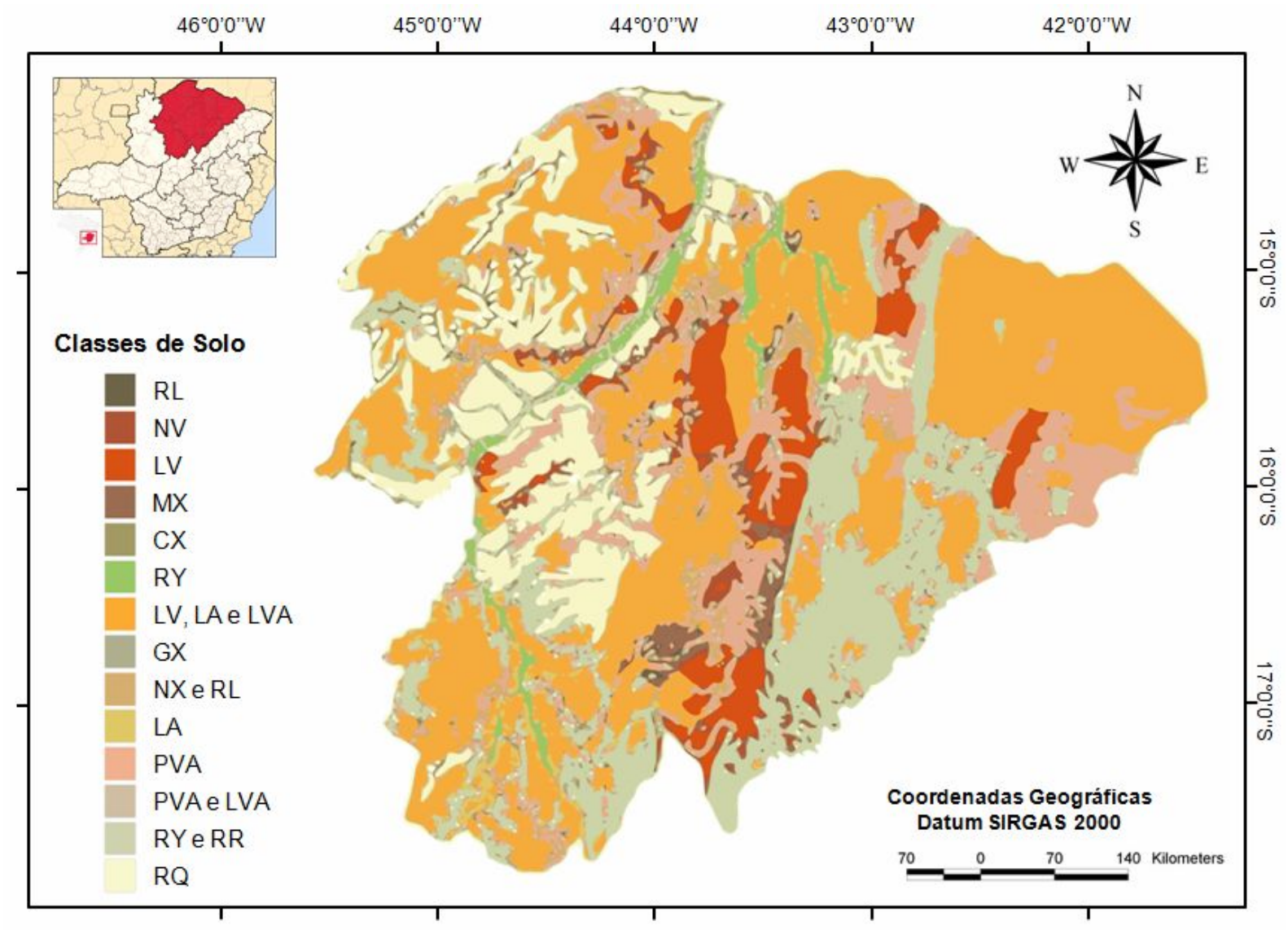

FIGURA 1. Mapa de classificação dos solos do Norte de Minas Gerais, de acordo com o Sistema Brasileiro de Classificação de Solos (SANTOS et al., 2013). Fonte: Elaborado pelos autores.

Legenda: Neossolo Litólico (RL); Nitossolo Vermelho (NV); Latossolo Vermelho (LV); Chernossolo Háplico (MX); Cambissolo Háplico (CX); Neossolo Flúvico (RY); Latossolo Amarelo (LA); Latossolo Vermelho-Amarelo (LVA); Gleissolo Háplico (GX); Nitossolo Háplico (NX); Argissolo Vermelho-Amarelo (PVA); Neossolo Regolítico (RR) e Neossolo Quartzarênico $(R Q)$.

Em diversas áreas predominam solos arenosos, classificados como Neossolos Quartzarênicos, caracterizados pela ausência de contato lítico dentro de $50 \mathrm{~cm}$ de profundidade, com sequência de horizontes $\mathrm{A}-\mathrm{C}$, apresentando textura areia ou areia franca em todos os horizontes até, no mínimo, a profundidade de 150 $\mathrm{cm}$ a partir da superfície do solo (SANTOS et al., 2013). Anteriormente classificados como Areias Quartzosas, os Neossolos Quartzarênicos representam $15 \%$ da área do Cerrado. São solos cuja estrutura é formada basicamente de grãos de quartzo, sendo, portanto, altamente suscetíveis à erosão, apresentam drenagem excessiva, baixa retenção de água e lixiviação de nutrientes (SPERA et al., 1999). Também ocorrem em grande expressão Argissolos Vemelho-Amarelos e Neossolos Flúvicos 
em associação a Neossolos Litólicos, esses últimos observados dominantemente em relevo forte ondulados e montanhosos, associados principalmente a afloramentos rochosos.

A avaliação das classes de aptidão agrícola das terras foi feita através do estudo comparativo entre os graus de limitação atribuídos às terras para cada fator agrícola e para cada nível de manejo, e os estipulados no quadro guia (Quadro 2), elaborados para atender à região de clima tropical úmido e semiárido. Cabe ressaltar que o quadro guia, no entanto, deve ser utilizado para uma orientação geral, em face do caráter subjetivo da interpretação, uma vez que está sujeita ao critério pessoal do usuário. A classificação da aptidão agrícola das terras deve ser feita em conjunto com as informações sobre as viabilidades de melhoramentos dos graus de limitações das condições agrícolas, exemplificadas no quadro guia (SILVA et al., 2010; WADT et al., 2016).

QUADRO 2. Graus de limitação e grupos e subgrupos de aptidão agrícola atribuídos às terras dos solos Mesorregião Norte de Minas para os níveis de manejo A, B e C, de acordo com Ramalho Filho; Beek (1995).

\begin{tabular}{|c|c|c|c|c|c|c|c|c|c|c|c|c|c|c|c|c|}
\hline \multirow[t]{2}{*}{ Código } & \multicolumn{3}{|c|}{$\begin{array}{l}\text { Deficiência em } \\
\text { fertilidade }\end{array}$} & \multicolumn{3}{|c|}{$\begin{array}{c}\text { Deficiência de } \\
\text { água }\end{array}$} & \multicolumn{3}{|c|}{$\begin{array}{c}\text { Deficiência } \\
\text { em oxigênio }\end{array}$} & \multicolumn{3}{|c|}{$\begin{array}{l}\text { Susceptibilidade } \\
\text { à erosão }\end{array}$} & \multicolumn{3}{|c|}{$\begin{array}{l}\text { Impedimentos } \\
\text { à mecanização }\end{array}$} & \multirow[t]{2}{*}{ Classe } \\
\hline & $\bar{A}$ & $B$ & $\mathrm{C}$ & $A$ & $B$ & C & $A$ & B & $\mathrm{C}$ & $A$ & $B$ & $\mathrm{C}$ & $A$ & $B$ & C & \\
\hline PVd4 & $\bar{M} / \mathrm{F}$ & M1 & $\mathrm{N} / \mathrm{L} 2$ & $\mathrm{~L} / \mathrm{M}$ & L/M & $\mathrm{L} / \mathrm{M}$ & $\mathrm{N}$ & $\mathrm{N}$ & $\mathrm{N}$ & L/M & N1 & N1 & $\mathrm{L}$ & $\mathrm{L}$ & $\mathrm{L}$ & $2(a b c)$ \\
\hline PVd4 & $\mathrm{F}$ & M1 & L2 & M & M & M & $\mathrm{N}$ & $\mathrm{N}$ & $\mathrm{N}$ & $\mathrm{N} / \mathrm{L}$ & N1 & $\mathrm{N} 1$ & $\mathrm{~N} / \mathrm{L}$ & $\mathrm{N} / \mathrm{L}$ & $\mathrm{N} / \mathrm{L}$ & $2(b) c$ \\
\hline PE9 & $\mathrm{F}$ & L/M1 & N2 & L & L & L & $\mathrm{N}$ & $\mathrm{N}$ & $\mathrm{N}$ & $\mathrm{N} / \mathrm{L}$ & N1 & N1 & $\mathrm{N} / \mathrm{L}$ & $\mathrm{N} / \mathrm{L}$ & $\mathrm{N} / \mathrm{L}$ & $2(b) c$ \\
\hline PE5 & L/M & N1 & N1 & $\mathrm{N} / \mathrm{L}$ & $\mathrm{N} / \mathrm{L}$ & $\mathrm{N} / \mathrm{L}$ & L/M & L1 & L1 & $\mathrm{N} / \mathrm{L}$ & $\mathrm{N} / \mathrm{L}$ & $\mathrm{N} / \mathrm{L}$ & M & M & $\mathrm{M}$ & $2 a b(c)$ \\
\hline $\mathrm{Ca} 1$ & $\mathrm{~L} / \mathrm{N}$ & N1 & N1 & $\mathrm{M}$ & $\mathrm{M}$ & M & $\mathrm{N}$ & $\mathrm{N}$ & $\mathrm{N}$ & $M$ & L/M1 & $\mathrm{N} / \mathrm{L} 2$ & $M$ & $M$ & $M$ & $2 a b(c)$ \\
\hline Re3 & L & N1 & N1 & L & L & L & L & L & L & L & $\mathrm{N} / \mathrm{L} 1$ & $\mathrm{~N} / \mathrm{L} 1$ & $\mathrm{~L} / \mathrm{M}$ & $\mathrm{L} / \mathrm{M}$ & L/M & $2 a b(c)$ \\
\hline $\mathrm{Ae} 2$ & L & N1 & N1 & M & M & M & $\mathrm{N}$ & $\mathrm{N}$ & $\mathrm{N}$ & $\mathrm{N} / \mathrm{L}$ & N1 & N1 & $\mathrm{N}$ & $\mathrm{N}$ & $\mathrm{N}$ & $2 a b c$ \\
\hline LVe1 & $\mathrm{F}$ & M1 & $\mathrm{N} / \mathrm{L} 2$ & L & L & L & $\mathrm{N}$ & $\mathrm{N}$ & $\mathrm{N}$ & L & N1 & N1 & L & L & L & $2 b(c)$ \\
\hline LVa25 & L/M & N1 & N1 & L & L & L & L & L & L & $\mathrm{M} / \mathrm{F}$ & M1 & L/M2 & $M$ & $M$ & $\mathrm{M}$ & $3(a b)$ \\
\hline LEe5 & $\mathrm{F}$ & M1 & L2 & L & L & L & $\mathrm{N}$ & $\mathrm{N}$ & $\mathrm{N}$ & $\mathrm{N} / \mathrm{L}$ & N1 & N1 & $\mathrm{N} / \mathrm{L}$ & $\mathrm{N} / \mathrm{L}$ & $\mathrm{N} / \mathrm{L}$ & 2(b)c \\
\hline LEa1 & $\mathrm{F}$ & M1 & L2 & L & L & L & $\mathrm{N}$ & $\mathrm{N}$ & $\mathrm{N}$ & L & N1 & N1 & L/M & $\mathrm{L} / \mathrm{M}$ & L/M & $3(\mathrm{bc})$ \\
\hline LVa23 & MF & $\mathrm{M} / \mathrm{F} 1$ & L/M2 & $M$ & M & M & $\mathrm{N}$ & $\mathrm{N}$ & $\mathrm{N}$ & L & $\mathrm{N} / \mathrm{L} 1$ & N2 & $\mathrm{N} / \mathrm{L}$ & $\mathrm{N} / \mathrm{L}$ & $\mathrm{N} / \mathrm{L}$ & $3(c)$ \\
\hline LEe7 & $\mathrm{F}$ & $\mathrm{F}$ & $\mathrm{F}$ & $M$ & M & M & L & L & L & M & L/M1 & L/M1 & $\mathrm{F}$ & $\mathrm{F}$ & $\mathrm{F}$ & $4(p)$ \\
\hline PE9 & $\mathrm{F}$ & $\mathrm{F}$ & $\mathrm{F}$ & L & L & L & L & L & L & $\mathrm{M} / \mathrm{F}$ & M1 & M1 & $\mathrm{F}$ & $\mathrm{F}$ & $\mathrm{F}$ & $4(p)$ \\
\hline LVa19 & L & L & L & $\mathrm{F}$ & $\mathrm{F}$ & $\mathrm{F}$ & $\mathrm{N}$ & $\mathrm{N}$ & $\mathrm{N}$ & L/M & L1 & $\mathrm{N} / \mathrm{L} 2$ & $\mathrm{~L}$ & L & L & $4(p)$ \\
\hline LVa7 & L & L & L & $\mathrm{F}$ & $\mathrm{F}$ & $\mathrm{F}$ & $\mathrm{N}$ & $\mathrm{N}$ & $\mathrm{N}$ & $\mathrm{M} / \mathrm{F}$ & L1 & L1 & $M$ & M & M & $4(p)$ \\
\hline LVa30 & $\mathrm{M}$ & L/M1 & L/M1 & $\mathrm{F}$ & $\mathrm{F}$ & $F$ & $\mathrm{~N}$ & $\mathrm{~N}$ & $\mathrm{~N}$ & $\mathrm{M} / \mathrm{F}$ & M1 & M1 & M & $\mathrm{M}$ & M & $4(p)$ \\
\hline LEa5 & L & L & L & $\mathrm{F}$ & $\mathrm{F}$ & $\mathrm{F}$ & $\mathrm{N}$ & $\mathrm{N}$ & $\mathrm{N}$ & L & N1 & N1 & $\mathrm{N} / \mathrm{L}$ & $\mathrm{N} / \mathrm{L}$ & $\mathrm{N} / \mathrm{L}$ & $4(p)$ \\
\hline Ae2 & MF & MF & MF & MF & MF & MF & $\mathrm{N}$ & $\mathrm{N}$ & $\mathrm{N}$ & $\mathrm{F}$ & $\mathrm{F}$ & $\mathrm{F}$ & $\mathrm{M} / \mathrm{F}$ & $\mathrm{M} / \mathrm{F}$ & $\mathrm{M} / \mathrm{F}$ & $5(n)$ \\
\hline Ra8 & L/M & L/M & L/M & $\mathrm{F}$ & $\mathrm{F}$ & $\mathrm{F}$ & $\mathrm{N}$ & $\mathrm{N}$ & $\mathrm{N}$ & $\mathrm{N} / \mathrm{L}$ & N1 & N1 & $\mathrm{N} / \mathrm{L}$ & $\mathrm{N} / \mathrm{L}$ & $\mathrm{N} / \mathrm{L}$ & $5(\mathrm{~s})$ \\
\hline TRSe4 & L & L & L & $\mathrm{N}$ & $\mathrm{N}$ & $\mathrm{N}$ & $\mathrm{F}$ & $\mathrm{F}$ & $\mathrm{F}$ & $\mathrm{N} / \mathrm{L}$ & $N / L$ & $\mathrm{~N} / \mathrm{L}$ & $\mathrm{F}$ & $\mathrm{F}$ & $\mathrm{F}$ & $5 n$ \\
\hline AQa4 & M & M & M & $\mathrm{F}$ & $\mathrm{F}$ & $\mathrm{F}$ & $\mathrm{N}$ & $\mathrm{N}$ & $\mathrm{N}$ & MF & MF & MF & MF & MF & MF & 6 \\
\hline TRSe1 & L/M & L/M & L/M & M & M & M & $\mathrm{N}$ & $\mathrm{N}$ & $\mathrm{N}$ & EF & EF & EF & MF & MF & MF & 6 \\
\hline TRSa & $\mathrm{F}$ & $\mathrm{F}$ & $F$ & M & M & M & $\mathrm{L}$ & $\mathrm{L}$ & $\mathrm{L}$ & MF & MF & MF & MF & MF & MF & 6 \\
\hline
\end{tabular}

Legenda: Nulo (N); Ligeiro (L); Moderado (M); Forte (F); Muito Forte (MF); Extremamente Forte (EF).

Tendo em vista práticas agrícolas ao alcance da maioria dos agricultores, são considerados três níveis de manejo, visando diagnosticar o comportamento das terras em diferentes níveis tecnológicos. Por manejo de tipo A (primitivo) entende-se um manejo baseado em práticas agrícolas que refletem um baixo nível técnicocultural. Praticamente não há aplicação de capital para melhoramentos e conservação das terras e das lavouras. As práticas agrícolas dependem 
fundamentalmente do trabalho braçal, podendo ser utilizada alguma tração animal com implementos agrícolas simples (RAMALHO FILHO; BEEK, 1995).

$O$ nível de manejo $B$ (pouco desenvolvido) caracteriza-se pela modesta aplicação de capital e de resultados de pesquisas para manejo, melhoramento e conservação das condições das terras e das lavouras. As práticas agrícolas neste nível de manejo incluem calagem e adubação com NPK, tratamentos fitossanitários simples e mecanização com base na tração animal ou na tração motorizada, apenas para desbravamento e preparo inicial do solo. Já o nível de manejo $\mathrm{C}$ é baseado em práticas agrícolas que refletem um alto índice tecnológico. Caracteriza-se pela aplicação intensiva de capital e de resultados de pesquisa para manejo, melhoramento e conservação das condições das terras e lavouras. A motomecanização está presente nas diversas fases da operação agrícola (RAMALHO FILHO; BEEK, 1995; DELARMELINDA, 2011;2014; WADT, 2013).

Mediante o exposto foram feitas recomendações de uso das terras do Norte de Minas baseadas nos resultados obtidos na avaliação da aptidão agrícola das terras e do panorama da região para os diferentes níveis de manejo.

\section{Nível de manejo A}

Grupo 2: O grupo 2 é o de aptidão regular para lavoura, com isso é recomendado para o agricultor $A$, o cultivo de espécies rústicas, espécies que apresentam baixa demanda de nutrientes e mais tolerantes às adversidades ambientais, por exemplo, mandioca (Manihot esculenta Crantz), feijão-caupi (Vigna unguiculata (L.) Walp.), milho-crioulo (Zea mays L.) e batata-doce (Ipomoea batatas L.). Outra possibilidade seria o extrativismo de frutos do Cerrado por meio do aproveitamento sustentável de uma grande diversidade de espécies como o araçá (Psidium araca), pitomba (Talisia esculenta), a macambira (Bromeliaceae), a cagaita (Eugenia disenterica), o coquinho-azedo (Butia capitata), a mangaba (Hancornia speciosa), o maracujá nativo (Passiflora cincinatta) o panã (Annona crassiflora) e o pequi (Caryocar brasiliensis), possui grande potencial para se tornar um elemento estratégico à conservação dos ecossistemas e geração de renda para as comunidades do meio rural.

Grupo 3: O grupo 3 representa terras com aptidão restrita para lavoura. São indicadas culturas que demandam manejo mais simples, como milho crioulo (Zea mays $L$ ), palma forrageira (Opuntia cochenillifera), sorgo forrageiro (Sorghum bicolor) e mandioca (Manihot esculenta Crantz), além do aproveitamento de espécies nativas, como mencionado no grupo anterior.

Grupo 5 - 5n e 5(n): São solos de difícil cultivo, com declividade que propicia a erosão e dificulta a mecanização. Recomenda-se a criação de animais que necessitam de pouca água, como é o caso dos caprinos e ovinos, que além de fornecer leite, pele e carnes, possuem importância histórica e sócio-cultural. Outro aspecto importante é que esse agricultor faça um uso racional das pastagens naturais por meio do pastejo rotacionado.

\section{Nível de manejo B}

Grupo 2: Para o agricultor de nível B, mediante suas melhores condições de conhecimento e tecnologia é recomendado o cultivo de mamona (Ricinus communis L.) e pinhão-manso (Jatropha curcas L.) para produção de biodiesel, e culturas como feijão (Phaseolus vulgaris L), milho (Zea mays), algodão (Gossypium hirsutum L.) e mandioca (Manihot esculenta Crantz). Recomenda-se plantio em nível, manejo e 
incorporação dos restos culturais, assim como, rotação de culturas e adubação verde. Outra recomendação seria o plantio de espécies frutíferas nativas em sistemas agroflorestais (SAFs), que englobam uma diversidade de plantas nativas e exóticas, de ciclos de vida curto, médio e longo, buscando "imitar" a sucessão natural da vegetação dos ecossistemas; e adensamento de áreas naturais com espécies aproveitáveis. As técnicas ecológicas de plantio se apresentam com maior versatilidade e flexibilidade, permitindo uma melhor adaptação às realidades ambiental, social e econômica desses agricultores. Adicionalmente, possuem um grande potencial para a manutenção e melhoria da qualidade e dos serviços ambientais, relacionada aos recursos hídricos, fertilidade dos solos e fixação de carbono.

Considerando que este agricultor vai dispor de recursos financeiros e de tecnologias, inacessíveis aos extrativistas, o agricultor com nível de manejo B, cooperativado, tem nesse solo maiores possibilidades de produção em sistemas adaptados às condições locais. É recomendada a agregação de valor aos produtos extrativos do Cerrado através do beneficiamento desses produtos, como, por exemplo, a transformação de frutas em polpas, geleias, doces ou licores. A apicultura também é indicada como uma atividade produtiva que pode ser desenvolvida em áreas de vegetação nativa e que requer certo nível de conhecimento para sua realização.

Uma possibilidade viável para produtores de mandioca seria a continuidade da cadeia de produção por meio do processamento da mandioca em cooperativas agroindustriais. Com isso, haverá melhor flexibilidade da produção além de acréscimo na geração de renda. $\mathrm{O}$ agricultor de mandioca cooperativado terá mais espaço para o aprimoramento de técnicas produtivas, uma vez que, haverá maior troca de experiências entre os mesmos. Os produtos resultantes deste processamento serão importantes para o abastecimento do mercado regional que culturalmente expressa grande demanda por farinhas e féculas de mandioca.

Grupo 3: Pode ser feito também o cultivo de espécies mais rústicas, com maior resistência ao clima seco, como sorgo (Sorghum bicolor (L.) Moench) e algodão (Gossypium hirsutum L.). Podendo o agricultor dispor de insumos simples, recomenda-se a este aproveitar as poucas chuvas que ocorrem na região utilizando de uma cultura regional de ciclo curto, como exemplo o plantio do milho (Zea mays), recomenda-se ainda que o mesmo promova manutenção da cobertura vegetal. Para melhorar as características do solo, o produtor pode fazer o uso de adubação verde e adubações de cobertura com $\mathrm{N}$ e K, podendo amenizar o problema da fertilidade.

Grupo 4: $O$ grupo 4 é aquele referente à aptidão para pastagem plantada, com isso recomenda-se para o agricultor $\mathrm{B}$ o cultivo de eucalipto por fomento, lichia (Litchi chinensis), seringueira (Hevea brasiliensis L.) e pupunha (Bactris gasipaes Kunth). Implantação de sistemas silvipastoris, com a implantação de pastagens (Brachiaria spp.) e bovinocultura de leite e corte, consorciados com o plantio de espécies arbóreas fixadoras de nitrogênio, freijó (Cordia goeldiana), Louro amarelo (Cordia alliodora), proporcionando sombreamento para o gado e posterior exploração da madeira. Também poderá ser utilizado, como planta forrageira e adubação verde, espécies como feijão guandú (Cajanus cajan) que é uma planta tolerante a solos com baixa fertilidade e ambientes com condições de seca.

Uma outra sugestão é a produção de leucena (Leucaena leucacephala), usada para forragem, madeira e melhoramento do solo. Por serem solos indicados para pastagem plantada, poderão ser recomendados recursos para melhoria das 
mesmas como: adubação, pastejo rotacionado com o uso de piquetes, consórcio de leguminosas e gramíneas, possibilitando um aumento de produtividade do rebanho.

Grupo 5-5(s): $O$ grupo 5(s) representa as terras com aptidão restrita para silvicultura. Neste contexto, o Eucalipto (espécie exótica originária da Austrália que possui alta taxa de crescimento e fácil adaptabilidade a condições edafo-climática adversas) é uma cultura recomendada aos agricultores de nível $\mathrm{C}$, pois suas características facilitam a sua reprodução em larga e escala. Um dos fatores que reforçam esta recomendação é a forte vocação siderúrgico-florestal do Estado que incentiva a cultura dessa espécie no Norte de Minas através de subsídios. A produção de Eucalipto constitui ainda uma maneira de se preservar a vegetação nativa da região, pois diminui a pressão ocasionada pela necessidade de combustível lenhoso para os fornos siderúrgicos.

\section{Nível de manejo C}

Grupo 2: Por ser um nível de manejo que dispõe de maior grau de tecnologia são recomendadas práticas como plantio direto, em nível, rotação de culturas e adubação verde que causam menor impacto ambiental, além das práticas convencionais de correção da acidez e elevação da fertilidade do solo. É indicado cultivo de espécies de alto valor agregado, plantio cana-de-açúcar (Saccharum officinarum), soja (Glycine max L.), milho (Zea mays), mandioca (Manihot esculenta Crantz) e algodão (Gossypium hirsutum L.). Também pode realizar criação intensiva de gado, podendo adotar o sistema agrosilvipastoril.

Grupo 3: Tendo esses agricultores maiores recursos e podendo utilizar melhor tecnologia, são indicadas as mesmas espécies do nível $B$, além do plantio de frutíferas em curva de nível consorciadas com leguminosas ou outras plantas que possibilitem aumento no teor de matéria orgânica e CTC, e assim gradual melhoria da fertilidade do solo.

Grupo 4: Por serem solos indicados para pastagem plantada, recomenda-se a criação de bovinos de leite e corte nessa área com pastoreio controlado/rotacionado, reduzindo a pressão de pastejo na área, uso de piquete e consórcio de leguminosas e gramíneas, possibilitando um aumento na produtividade de caprinos. Nestas áreas também se recomenda a implantação de silvicultura adotando sistema agrossilvipastoril.

Grupo 5: Nesse grupo, estão áreas que apresentam um bom potencial para silvicultura. Recomenda-se plantio de eucalipto com estabelecimento de um manejo silvipastoril, com caprinos que mais se adaptam as condições de relevo local. 


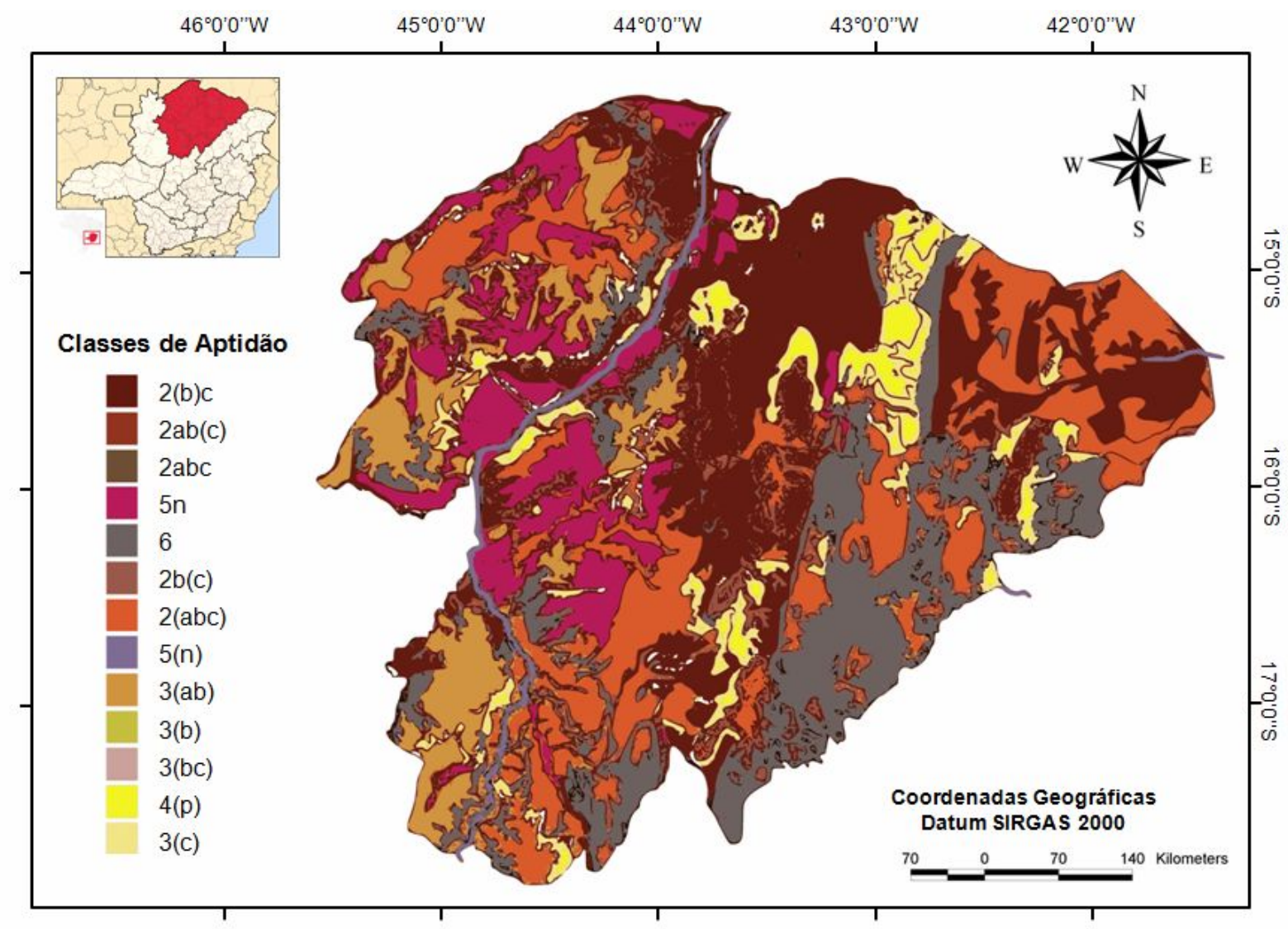

FIGURA 2. Mapa de classes de aptidão agrícola dos solos do Norte de Minas Gerais, de acordo com Ramalho Filho; Beek (1995). Fonte: Elaborado pelos autores.

A presença da agricultura familiar na região do Cerrado é pequena se comparada às regiões brasileiras de ocupação mais antiga. Sem dúvida, a impressão de um "vazio demográfico" no Cerrado foi um dos pretextos para a colonização de suas terras pela agricultura empresarial de larga escala. $O$ esvaziamento, no entanto, tem ocorrido pela expulsão de seus habitantes antigos e da diminuição do emprego e ocupação no campo (LEITE et al., 2012). Ainda assim, persiste a produção agrícola em pequena escala no Cerrado, com potencial gerador de grandes benefícios sociais e ambientais.

No Norte de Minas, diversas cooperativas veem desenvolvendo experiências junto a grupos de famílias de trabalhadores rurais, com enfoque na agricultura sustentável a partir da valorização e fortalecimento dos sistemas produtivos tradicionais (LEITE et al., 2012; CORREIA; LIMA, 2015). O cooperativismo facilita a compra de insumos, faz uso racional de equipamentos, racionaliza as atividades pós-colheita e promove escoamento eficiente dos produtos, caracterizando nesse caso, no sistema de aptidão agrícola das terras, a um nível de manejo B. Nos dias atuais, o surgimento desta forma de associativismo constitui-se numa busca pela melhoria da qualidade vida do agricultor, e, numa visão mais ampla, coloca-se como meio alternativo de desenvolvimento local, visto que apresenta uma relação de afinidade com o conceito de capital empresarial, ou seja, em sua essência, o cooperativismo caracteriza-se por uma forma de produção e distribuição de riquezas 
baseada em princípios como a ajuda mútua, a igualdade, a democracia e a equidade.

Por outro lado, a agricultura empresarial, também conhecida como agronegócio, baseia-se na produção em larga escala das chamadas "commodities" agrícolas, que são produzidas em grandes extensões de terra. Como esses agricultores detêm elevado poder econômico, em termos de tecnologia, a agricultura empresarial faz uso intensivo de maquinário, fertilizantes químicos e pesticidas, correspondendo, no sistema de aptidão agrícola, sistema de Manejo C.

A grande diversidade biológica, animal, vegetal, os diversos tipos de paisagens, fazem do Norte de Minas uma região rica com muitas características peculiaridades e com potencial para o desenvolvimento sustentável. Nessa região, a agricultura familiar representa boa parte dos estabelecimentos agrícolas, dedicada basicamente à produção de alimentos que abastecem o mercado interno com técnicas geralmente rudimentares, sem um elevado grau tecnológico, correspondendo, no sistema de aptidão agrícola, ao nível de manejo A.

Por considerar os fatores econômicos, sociais e ambientais para a classificação das terras, a aplicação do Sistema de Avaliação da Aptidão Agrícola das Terras constitui uma importante ferramenta para os problemas sociais e econômicos da região. Por meio da avaliação da aptidão das terras e elaboração de mapas de adequação do uso das mesmas é possível planejar as atividades que exercem pressão sobre os recursos naturais, contribuindo para a mitigação da sua degradação (POELKING, et al. 2015).

\section{CONCLUSÃO}

A mesorregião Norte de Minas apresenta terras com aptidão para cultivo silvícola e terras que permitem o cultivo agrícola. Não sendo encontradas, todavia, terras com aptidão boa para lavoura.

As terras com aptidão regular ou restritas para lavouras foram observadas nas microrregiões Salinas, Janaúba e Pirapora. Enquanto as classes de pior aptidão agrícola encontram-se associadas às microrregiões de Grão Mogol e Bocaiúva, tendo como principais limitações, deficiência hídrica, fertilidade, mecanização e susceptibilidade a erosão. Diante disso, se faz necessário assegurar práticas que possibilitem a exploração sustentável dos recursos naturais, para o desenvolvimento integrado da região Norte de Minas.

O reconhecimento de iniciativas como cooperativas de agricultores familiares possibilita, por meio do beneficiamento e comercialização dos produtos nativos e da integração entre diversos setores, a valorização das potencialidades da região e o seu desenvolvimento sustentável. A formação de cooperativas de produção de agricultores familiares traz benefícios econômicos às famílias beneficiadas, induzindo melhoria das condições de vida dessa população, além de inclusão e permanência no campo. Entende-se, portanto, que uma dedicação especial deve ser dada a esse segmento pelo Estado através de políticas públicas que visem o desenvolvimento dessas regiões não urbanas, fornecendo mecanismos e subsídios para a permanência e a reprodução da população rural no campo. Deste modo, as cooperativas de agricultura familiar podem ser encaradas como uma opção positiva para o desenvolvimento e fortalecimento da agricultura. 


\section{REFERÊNCIAS}

ALMEIDA, F. F. M. O cráton do São Francisco. Revista Brasileira de Geociências, v. $7, \quad$ n. $4, \quad$ p. $349-364, \quad 2017$. Disponível em <http://ppegeo.igc.usp.br/index.php/rbg/article/view/11179/10638>.

ANJOS, L.H.C; JACOMINE, P.K.T.; SANTOS H.G.S.; OLIVEIRA, V.A.; OLIVEIRA, J.B.. Sistema Brasileiro de Classificação de Solos. In: KER, J.C. et al. Pedologia: Fundamentos. Viçosa: SBCS, p. 303-343, 2012.

CORREIA, J. R.; LIMA, H. C. de. Inovações Técnicas e suas Relações com Inovações Sociais e Institucionais no Norte de Minas: experiências com agricultores familiares em Rio Pardo de Minas, MG. Sustentabilidade em Debate, v. 6, n. 1, p. 138-154, 2015. http://dx.doi.org/10.18472/SustDeb.v6n1.2015.11489

ANGELIS FILHO, J. S. D. Políticas locais para o des-envolvimento no norte de minas: uma análise das articulações local; supralocal. Mestrado em Gestão em Desenvolvimento Rural e Agricultura Sustentável, Universidad Catolica de Temuco, Temuco, Chile. 142p. 2005

DELARMELINDA, E. A.; WADT, P. G. S.; ANJOS, L. H. C.; MASUTTI, C. S. M.; DA SILVA, Ê. F.; BARROS, M.; DO COUTO, W. H. Aplicação de sistemas de avaliação da aptidão agrícola das terras em solos do Estado do Acre, Amazônia. Biota Amazônia, v. 4, n. 2, p. 87-95, 2014. http://dx.doi.org/10.18561/21795746/biotaamazonia.v4n2p87-95

DELARMELINDA, E. A.; WADT, P. G. S.; ANJOS, L. H. C.; MASUTTI, C. S. M.; SILVA, E. F.; SILVA, M. B. E.; et al. Avaliação da Aptidão Agrícola dos Solos do Acre por Diferentes Especialistas. Revista Brasileira de Ciência do Solo, v. 35, n. 36, p. 1841-1853, 2011. http://dx.doi.org/10.1590/S0100-06832011000600001.

FLAUZINO, B. K.; MELLONI, E. G. P.; PONS, N. A. D. Mapeamento da capacidade de uso da terra como contribuição ao planejamento de uso do solo em sub-bacia hidrográfica piloto no sul de minas gerais. Geociências, v. 35, n. 2, p. 277-287, 2016.

GONÇALVES, C. V. P. Breve ensaio sobre Desenvolvimento e Sustentabilidade a partir da Geografia do Norte de Minas. In: DAYRELL, Carlos; A. LUZ. Cláudia (orgs.) Cerrado e Desenvolvimento: Tradição e Atualidade. Montes Claros. Ed. Unimontes, 2000.

GONÇALVES, F. A. A.; RODET, J. G. M. A.; JUNIOR, A. P. M. Carste suspenso e geomorfologia de longo termo. A região cárstica dos currais de pedras, Jequitaí-MG. Revista Brasileira de Geomorfologia, v. 18, n. 2, 2017. http://dx.doi.org/10.20502/rbg.v18i2.817

IBGE - Censo Agropecuário do Brasil 2015. Disponível em: www.ibge.gov.br.

JACOMINE, P. K. T.; CAVALCANTI, A. C.; FORMIGA, R.; SILVA, F. B. R.; BURGOS, N.; MEDEIROS, L. A. R.; PESSÔA, S. Levantamento exploratório-reconhecimento de solos do Norte de Minas Gerais: área de atuação da SUDENE. Embrapa SolosSéries anteriores (INFOTECA-E). 1979, 407p. 
JOLY, A. B. Conheça a Vegetação Brasileira. USP, São Paulo, 1970

KÄMPF, N.; CURI, N. Formação e evolução do solo (Pedogênese). In: KER, J.C. et al. Pedologia: Fundamentos. Viçosa: SBCS, p. 207-302, 2012.

LEITE, M. E., ALMEIDA, J. W. L.; SILVA, R. F. da. Análise espaço-temporal do eucalipto no Norte de Minas Gerais nos anos de 1986, 1996 e 2010. GeoTextos, v. 8, n. 2, p. 59-74, 2012. http://dx.doi.org/10.9771/1984-5537geo.v8i2.5931

MARTINS, S. Mapeamento de vegetação do Estado de Minas Gerais utilizando dados modis, INPE, São José dos Campo, 2006.

NEVES, W. V.; MENEZES, E. P.; OLIVEIRA, F. S. de.; AUGUSTIN, C. H. R. R.; ARANHA, P. R. A. Estudo das Coberturas Superficiais na Interface Cerrado-Vereda no Norte de Minas Gerais. Revista Brasileira de Geomorfologia, v. 16, n. 3, p. 351367, 2015. http://dx.doi.org/10.20502/rbg.v16i3.765

PEREIRA, L. C.; LOMBARDI NETO, F. Avaliação da aptidão agrícola das terras: proposta metodológica. Jaguariúna: Embrapa Meio Ambiente, 2004. 36 p.

POELKING, E. L.; DALMOLIN, R. S. D.; PEDRON, F. D. A.; FINK, J. R. Sistema de informação geográfica aplicado ao levantamento de solos e aptidão agrícola das terras como subsídios para o planejamento ambiental do município de Itaara, RS. Revista Árvore, v. 39, v. 2, p. 215-223, 2015. http://dx.doi.org/10.1590/010067622015000200001

RAMALHO FILHO, A.; BEEK, K. J. Sistema de avaliação da aptidão agrícola das terras. 3.ed. Rio de Janeiro, Empresa Brasileira de Pesquisa Agropecuária, 1995. $65 p$.

SANTOS, H. G. dos.; JACOMINE, P. K. T.; ANJOS, L. H. S. dos.; LUMBRERAS, J. F.; OLIVEIRA, J. B. de.; OLIVEIA, V. A. de.; COELHO, M. R..; ALMEIDA, J. A. de.; CUNHA, T. J. F. da. Proposta de atualização da segunda edição do Sistema Brasileiro de Classificação de Solos. Rio de Janeiro: Embrapa Solos, 2009. 66p.

SANTOS, H.G.; JACOMINE, P.K.T.; ANJOS, L.H.C.; OLIVEIRA, V.A.; LUMBRERAS, J.F.; COELHO, M.R.; ALMEIDA, J.A.; CUNHA, T.J.F.; OLIVEIRA, J.B. Sistema brasileiro de classificação de solos. $3^{\underline{a}}$ ed. Revisada e ampliada. Brasília, DF: Embrapa, 2013, 353p.

SILVA, E. B. D.; NOGUEIRA, R. E.; UBERTI, A. A. A. Avaliação da aptidão agrícola das terras como subsídio ao assentamento de famílias rurais, utilizando sistemas de informações geográficas. Revista Brasileira de Ciência do Solo, v. 34, n. 6, p. 1977-1990, 2010. http://dx.doi.org/10.1590/S0100-06832010000600022.

SILVA, G. J. C. D.; SOUZA, E. C.; MARTINS, H. E. D. P. Produção agropecuária em municípios de Minas Gerais (1996-2006): padrões de distribuição, especialização e associação espacial. Revista de Economia e Sociologia Rural, v. 50, n. 2, p. 333349, 2012. http://dx.doi.org/10.1590/S0103-20032012000200008 
SPERA, S. T.; REATTO, A.; MARTINS, E. D. S.; CORREIA, J. R.; CUNHA, T. J. F. Solos areno-quartzosos no cerrado: caracteristicas, problemas e limitacoes ao uso. Embrapa Cerrados-Documentos (INFOTECA-E), 1999.

WADT, P. G. S.; DO COUTO, W. H.; DELARMELINDA, E. A.; DOS ANJOS, L. H. C.; PEREIRA, M. G. Avaliação da aptidão agrícola das terras em solos sedimentares associados a argilas de alta atividade da Amazônia Sul-Ocidental. Biota Amazônia, v. 6 , n. $1, \quad$ p. $55-59, \quad 2016$. http://dx.doi.org/10.18561/21795746/biotaamazonia.v6n1p55-59

WADT, P. G. S. Payments for Farm Environmental Services. 1. ed. Plant City: CPS, 2013. 105p.

WADT, P. G. S.; OLIVEIRA, L. C.; OLIVEIRA, T. K.; CAVALCANTE, L. M. Sistema de aptidão das terras para recuperação ambiental: uma metodologia de planejamento ambiental. Rio Branco, AC: Embrapa Acre, 2004. 36p. 